tion of strength, but in the worst cases with great debility, requiring the strongest stimulants. And I believe this disease is caused by some deleterious substance or miasmata generated generally in the neighborhood of the soil; and that it is not contagious, for, giving things their due weight, it cannot be traced from one person to another, agreeably to the laws of contagion. And all the facts that tend to show it to be contagious, may be perfectly explained on true pathological principles, without being under the least necessity of consenting to its contagiousness.

September, 1832.

\title{
FOREIGN SUBSTANCE IN THE BACK.
}

\section{Extraction of Foreign Substunce from the Back. By H. A. BARRows, M.D., Leeds, Maine.}

[Communicated for the Boston Medical and Surgical Journal.]

JULy 14TH.-M. C-k, aged thirty-two, complains of pain and uneasiness in the right shoulder, and says it has troubled him for some weeks. Upon examining the part, find no discoloration or tumefaction, but a circumscribed soreness at the inferior angle of the right scapula, often attended with a sharp pain.

20th.-Patient no better; pain and soreness more severe; says it resembles the pain of rheumatism, and occasions much inconvenience about his labor. On examination, find there is a slight feeling of hardness, but the tumor is so stmall and indefinite that nothing can be made of it. Ordered a stimulating plaister.

24th.-Patient worse; the plaister has done no good; pain at times very acute; says he thinks he can feel something in his back like a penknife blade. Proceeded forthwith to search for the penknife, and find there is indeed that article or some other foreign body in the man's back. The slight feeling of hardness of the 20th had now become a well-defined oblong tumor, very superficial, and two inches in length. I now proceeded to extract this foreign substance, which proved to be, not exactly a penknife, but a long, well-formed sewing needle, perfect and entire.

BOSTON MEDICAL AND SURGICAL JOURNAL.

BOSTON, OCTOBER 3, 1832 .

\section{THE CHOLERA IN BOSTON.}

This disease can scarce be said to have existed as an epidemic in this city. There have been but few cases reported, and but one since the 21 st of September. Those that have been reported have been malignant, and mostly fatal. Most of them, however, occurred in or about Fessenden 